\title{
Identificando a flora do ambiente escolar e residencial
}

Identifying the flora of the school and residential environment

Érica da Cunha Maciel Milanez ${ }^{1}$, Elisa Mitsuko Aoyama², Débora Barreto Teresa Gradella ${ }^{3}$, Marco Antônio Andrade de Souza ${ }^{3}$

${ }^{1}$ Programa de Pós-Graduação em Rede em Ensino de Biologia (PROFBIO), Universidade Federal do Espírito Santo, São Mateus, Espírito Santo, Brasil.

${ }^{2}$ Universidade Federal do Espírito Santo, Departamento de Ciências Agrárias e Biológicas, São Mateus, Espírito Santo, Brasil.

${ }^{3}$ Universidade Federal do Espírito Santo, Departamento de Ciências da Saúde, São Mateus, Espírito Santo, Brasil.

Autor para correspondência: Érica da Cunha Maciel Milanez

EEEFM Geraldo Vargas Nogueira

Rodovia do Café Gether Lopes de Farias, Bairro Carlos Germano Naumann, 3716,

CEP 29.705-200, Colatina, Espírito Santo, Brasil

Tel: +55 27 99918-3880

Email: ericamilanez.milanez@hotmail.com

Submetido em 21/12/2020

Aceito em 21/12/2020

Health and Biosciences, v.1, n.3, Dez. 2020

Disponível em: https://periodicos.ufes.br/healthandbiosciences 


\title{
RESUMO
}

O trabalho trata-se de uma proposta de atividade investigativa sobre o tema Botânica para as aulas de Biologia do ensino médio, tendo como objetivo conhecer e identificar os grupos de plantas (Briófitas, Pteridófitas, Gimnospermas e Angiospermas) presentes no entorno escolar e residencial, compreendendo a evolução das plantas e minimizando os efeitos da cegueira botânica.

Palavras-chave: Biologia. Botânica. Evolução das Plantas. Atividade Investigativa. Ensino.

\begin{abstract}
The work is a proposal for an investigative activity on the subject of Botany for high school Biology classes with the objective of knowing and identifying the groups of plants (Bryophytes, Pteridophytes, Gymnosperms and Angiosperms) present in the school and residential surroundings, understanding the evolution of plants and minimizing the effects of botanical blindness.
\end{abstract}

Keywords: Biology. Botany. Evolution of Plants. Investigative Activity. Teaching.

Health and Biosciences, v.1, n.3, Dez. 2020

Disponível em: https://periodicos.ufes.br/healthandbiosciences 


\section{INTRODUÇÃO}

Amada por uns e odiada por outros, a Botânica é a área da Biologia que estuda o Reino Plantae, um reino extremamente variado e numeroso, compreendendo uma das mais antigas áreas das Ciências Naturais do mundo, com seres vivos eucariontes e autótrofos. Conhecer os grupos de plantas é de suma importância para compreender a evolução das plantas, a importância dos seres autotróficos para a existência de outros seres vivos e para a preservação e proteção da flora. Nos trabalhos desenvolvidos por Buckeridge (2015) e Salatino \& Buckeridge (2016), os autores enfatizam a importância de conhecermos e entendermos a ação das plantas para a existência humana e para um meio ambiente equilibrado, sendo a base da sustentação da vida. Salatino \& Buckeridge (2016) alertam que "as consequências da sociedade em não conhecer as suas plantas são drásticas" e citam dois exemplos:

1) o desconhecimento sobre a importância das árvores nas florestas e nas cidades (BUCKERIDGE, 2015) pode levar a população a deixar de se importar com o meio ambiente, o que nos colocaria no rumo de destruição dos biomas, levando os animais e a nós mesmos à extinção, pois só vivemos neste planeta porque as florestas estabilizam a biosfera, sequestrando carbono e produzindo o oxigênio que respiramos; 2) não reconhecer a importância e não conhecer o funcionamento das plantas nos leva a uma situação crítica para manter o que hoje praticamente sustenta a economia brasileira, o agrobusiness (SALATINO \& BUCKERIDGE, 2016, p. 180).

Todavia, o modelo de ensino tradicional, onde o professor é detentor do conhecimento e o aluno é ouvinte, ainda prevalece em muitas escolas brasileiras. Segundo Melo et al. (2012) é um desafio despertar o interesse dos alunos no ensino de Botânica, ainda mais se o método utilizado for o convencional, o que contribui de forma mais acentuada com a cegueira botânica, onde por muitas vezes sua presença passa despercebida ao nosso redor, sendo muito comum conotações pejorativas ao se referirem às plantas, como "mato" e "capoeira" (ARRAIAS et al., 2014).

Com os avanços da sociedade moderna, cada vez mais desenvolvida e industrializada, a incapacidade de perceber a importância das plantas é notória, conforme relatado por Neves et al. (2019), ao descreverem que caminhamos pelas ruas, praças, parques, alguns cercados por árvores, mas muitas vezes não as percebemos e não a reconhecemos como seres vivos. Ursi et al. (2018) afirmam que "aprender Botânica pode ampliar o repertório conceitual e cultural dos estudantes", mas para tal precisamos de metodologias ativas e inovadoras que mudem o cenário atual da educação. Contudo, faz-se necessário à contextualização do ensino, o resgate de conhecimentos prévios, paralelamente à sua relação no cotidiano.

Health and Biosciences, v.1, n.3, Dez. 2020

Disponível em: https://periodicos.ufes.br/healthandbiosciences 
Nesse sentido, o professor como mediador do processo de ensino aprendizagem precisar dar significados aos conteúdos, para que eles passem a fazer sentido para o aluno. Nesta perspectiva, o ensino por investigação vem ganhando cada vez mais espaço, por propiciar atividades que despertem o interesse do aluno e com o intuito de tornar as aulas de botânica mais atrativas, dinâmicas e prazerosas.

\section{OBJETIVOS}

$\checkmark$ Conhecer e identificar os grupos de plantas (Briófitas, Pteridófitas, Gimnospermas e Angiospermas).

$\checkmark$ Identificar os grupos de plantas presentes no entorno escolar e residencial.

$\checkmark$ Compreender a evolução das plantas.

$\checkmark$ Perceber e reconhecer as plantas ao nosso redor para minimizar os efeitos da cegueira botânica.

$\checkmark$ Estimular a curiosidade e interesse dos alunos.

\section{METODOLOGIA}

\section{Materiais utilizados}

- Câmera fotográfica ou de celular;

- Celular com aplicativo (PlantNet; Toque Tec; Gardênia; Leafsnap);

- Ficha técnica (Quadro 1);

- Envelope da evolução - Características evolutivas - Reino Plantae (Figura 3);

- Envelope da evolução - Cladograma das Plantas (Figura 4);

- 1 folha de papel A4 ou ofício colorido.

Turma: $3^{\circ}$ série do Ensino médio

Total de alunos: 40

Quantidade de aulas: 3 aulas

Desenvolvimento

\section{$1^{\circ}$ aula}

Health and Biosciences, v.1, n.3, Dez. 2020

Disponível em: https://periodicos.ufes.br/healthandbiosciences 
- Os alunos irão, individualmente, caminhar pelo pátio da escola e registrar com câmera fotográfica ou câmera de celular, imagens de plantas presentes no ambiente escolar e tirar quantas fotos acharem necessário.

- Após coletar as imagens, cada aluno deverá escolher qual foi a melhor imagem captada (escolher apenas uma). Neste instante haverá um momento de socialização da turma para que não haja imagens repetidas durante a escolha.

OBS: Tarefa para próxima aula

- Os alunos deverão trazer fotos ou imagens coloridas de plantas presentes no entorno residencial.

- Cada aluno deverá imprimir colorido ou revelar as imagens escolhidas do entorno escolar e do entorno residencial e trazer na próxima aula.

OBS: (Tamanho da imagem 10x15cm)

- Pedir aos alunos que façam um mapa conceitual das plantas, abordando as características gerais de cada grupo, assim como as semelhanças e diferenças entre eles, como: estrutura, ausência ou presença de vasos condutores, fase dominante e reprodução (Grupos Briófitas, Pteridófitas, Gimnospermas e Angiospermas).

- Os alunos deverão baixar no seu celular um aplicativo que identifica plantas.

Sugestões de aplicativos “identificador de plantas": PlantNet; Toque Tec; Gardênia; Leafsnap.

\section{$\mathbf{2}^{\mathbf{0}}$ aula}

Elaboração da Ficha Técnica (Quadro 1).

- Para preenchimento da ficha técnica será feito, novamente, um tour no pátio da escola para que os alunos possam, com o identificador de plantas, fazer a classificação das plantas escolhidas e verificar o seu nome popular e o seu nome científico.

- Cada aluno deverá classificar as plantas fotografadas em Briófitas, Pteridófitas, Gimnospermas e Angiospermas, podendo consultar o mapa conceitual elaborado por eles e/ou a internet, assim como preencher as outras informações da ficha técnica (Quadro 1).

Health and Biosciences, v.1, n.3, Dez. 2020

Disponível em: https://periodicos.ufes.br/healthandbiosciences 
Quadro 1. Ficha técnica

\begin{tabular}{|l|}
\hline FICHA TÉCNICA \\
\hline Nome popular: \\
\hline Nome científico: \\
\hline Gênero: \\
\hline Família: \\
\hline Classificação (Grupo): \\
\hline Habitat natural (origem): \\
\hline Características: \\
\hline Luminosidade: \\
\hline Curiosidades: \\
\hline Aluno fotógrafo: \\
\hline Disciplina: \\
\hline
\end{tabular}

- Após o preenchimento da ficha técnica os alunos deverão colar as imagens em tamanho $10 \times 15 \mathrm{~cm}$ - frente (imagem da planta) e verso (ficha técnica) - numa folha de papel colorido (Figura 1).

Dicas para o professor: Cortando a folha colorida ao meio dá para colar as duas imagens: a do entorno residencial numa metade e a do entorno escolar na outra metade.
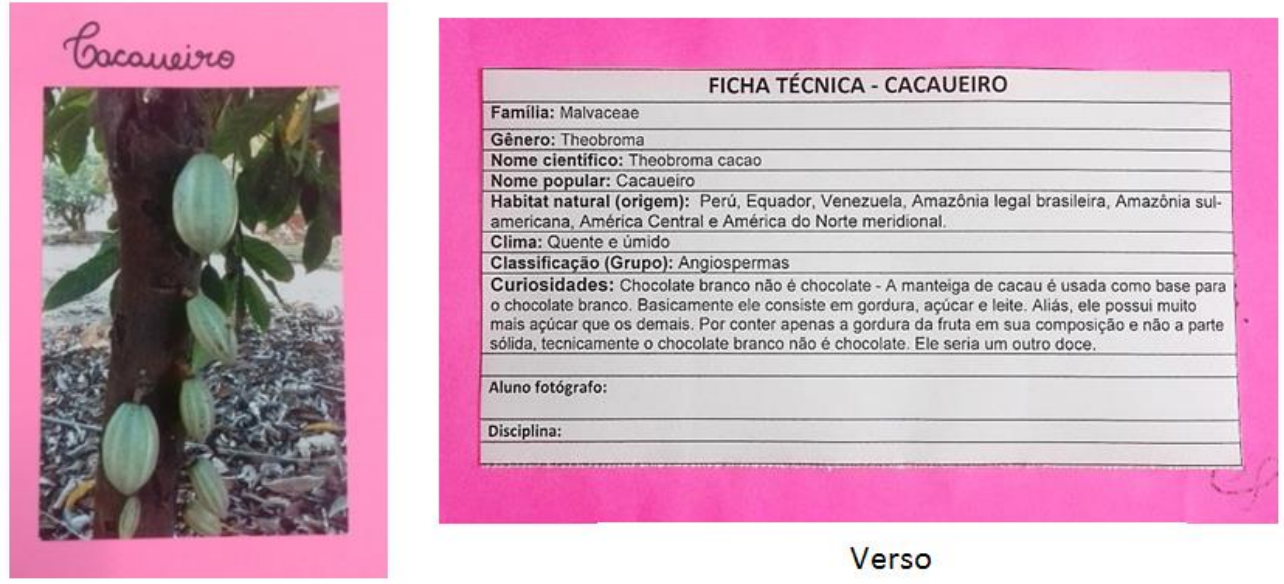

Frente

Figura 1. À esquerda um modelo de imagem fotografada pelos alunos no ambiente escolar e à direita, modelo de Ficha Técnica pesquisada e preenchida pelos alunos. 
- A sala será dividida em dois grandes grupos. Um grupo ficará com as fotografias das plantas presentes no entorno escolar e o outro grupo ficará com as fotografias das plantas do entorno residencial.

- Pedir para cada grupo separar as fotografias de acordo com classificação das plantas: Briófitas, Pteridófitas, Gimnospermas e Angiospermas (Figura 2).

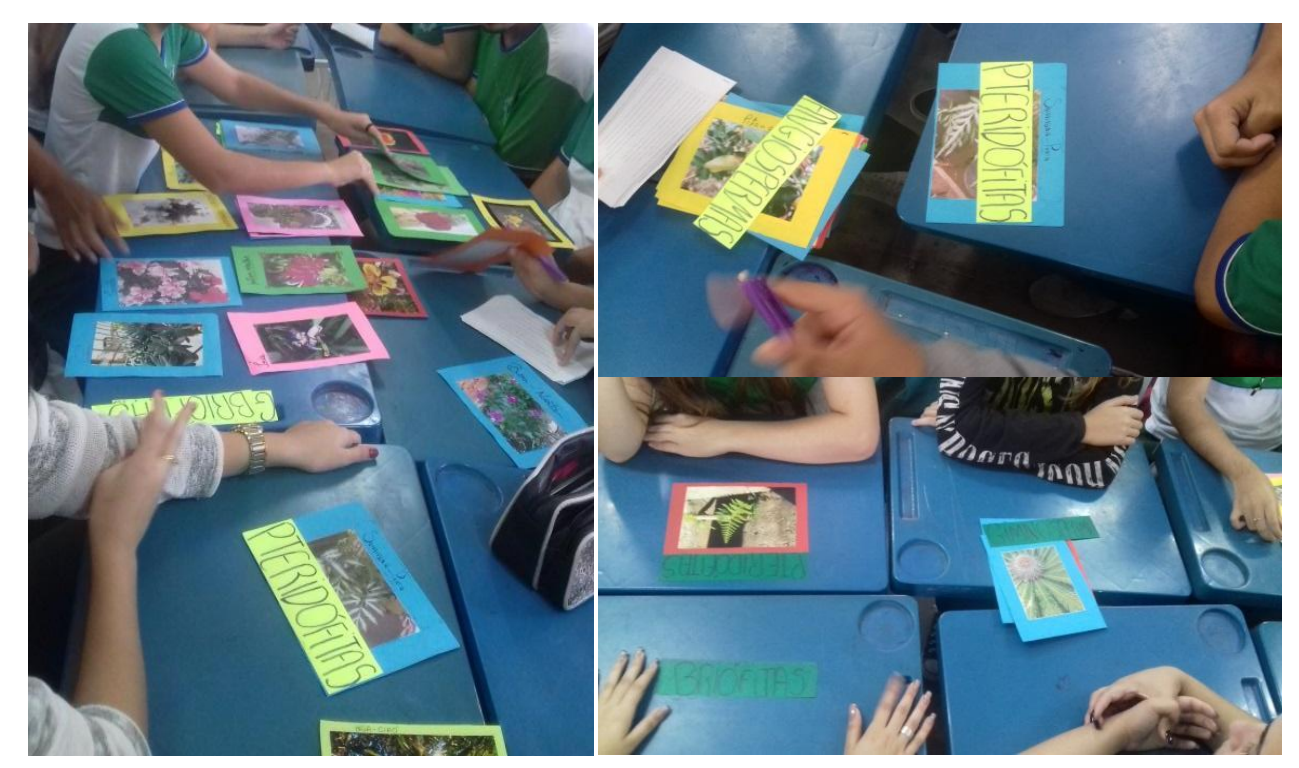

Figura 2. Alunos classificando as fotografias tiradas no ambiente escolar e residencial.

Professor/Sugestão: Com esta atividade dá para abordar taxonomia das plantas, evolução, reprodução, dispersão, ecologia das plantas, modo de vida e classificação.

\section{Perguntas Norteadoras}

1- Qual grupo de plantas está presente em abundância no entorno escolar? Por quê?

Reflexão: A presença ou ausência tem a ver com algum fator? Clima, tipo de solo, ecossistema, altitude, umidade, dispersão, reprodução?

2- Qual grupo de plantas está presente em abundância no entorno residencial? Por quê?

Reflexão: A presença ou ausência tem a ver com algum fator? Clima, tipo de solo, ecossistema,

Health and Biosciences, v.1, n.3, Dez. 2020

Disponível em: https://periodicos.ufes.br/healthandbiosciences 
altitude, umidade, dispersão, reprodução? Há diferença entre as plantas observadas no ambiente escolar e no entorno residencial? Por quê?

3- Qual grupo de plantas do entorno escolar possui menos exemplares? Por quê?

Reflexão: Verificar as imagens trazidas pelos alunos. Será que os alunos fotografaram de acordo com sua preferência? Será que tinham plantas que passaram despercebidas? Direcionar aos alunos a chegarem a essas conclusões. Por que a maioria das plantas fotografadas possui flores? Será que o maior grupo de plantas identificado teve um maior sucesso evolutivo? Por quê? Qual?

4- Qual grupo de plantas do entorno residencial possui menos exemplares? Por quê?

Reflexão: Verificar as imagens trazidas pelos alunos. Será que os alunos fotografaram de acordo com sua preferência? Será que tinham plantas que passaram despercebidas? Direcionar aos alunos a chegarem a essas conclusões. As plantas rasteiras, as aquáticas e os musgos passaram despercebidos? Alguma planta passou despercebida? Por que não há muitos exemplares?

5- Tem algum grupo de plantas que não foi fotografado/encontrado no entorno escolar? Por quê?

Reflexão: Dependendo da localidade será difícil fotografar exemplos de Briófitas e Pteridófitas. Instigar os alunos o porquê.

6- Tem algum grupo de plantas que não foi fotografado/encontrado no entorno residencial? Por quê?

Reflexão: Dependendo da localidade será difícil fotografar exemplos de Briófitas e Pteridófitas. Instigar os alunos o porquê. No entorno residencial talvez esses grupos até existam, mas o que ocorreu, por que não as fotografaram?

7- O que seria do mundo sem as plantas? Será que conseguiríamos viver sem elas? Qual a Health and Biosciences, v.1, n.3, Dez. 2020 
importância das plantas para os seres vivos e para o meio ambiente?

Reflexão: Professor, instigue os alunos se as plantas são seres vivos ou não. Quais características permitem afirmar ou negar seus argumentos? Instigar os alunos sobre a idade geológica das plantas. Será que elas são antigas ou recentes na história do planeta? Relacionálas a processos vitais para a sobrevivência de outros seres vivos como fotossíntese e cadeia alimentar, assim como fatores essenciais para o meio ambiente equilibrado, como a formação de rios voadores (evapotranspiração), a diminuição da temperatura "ar condicionado natural", sua capacidade de reter água no solo por mais tempo, através de suas raízes, contribuindo, assim, para com a preservação das nascentes, além de evitar processos de erosão.

- O professor deve conduzir o debate de acordo com a resposta dos alunos, instigando-os a todo instante, fazendo com que participem e se sintam motivados, constantemente.

- Após os questionamentos, entregar aos grupos envelopes (Quadro 2 e Figura 3) contendo um molde do cladograma das plantas e várias palavras e pedir que os grupos, a partir de suas observações, montem o cladograma, indicando a evolução das plantas e insiram as características que forem surgindo ao longo do tempo.

$O B S$ : Nesta atividade os alunos deverão usar conhecimentos prévios, onde em grupos devem debater, questionar a ordem evolutiva das características presentes ou ausentes em determinados grupos de plantas.

Quadro 2. Envelope da evolução - Características evolutivas - Reino Plantae.

\begin{tabular}{|l|l|}
\hline TRAQUEÓFITAS/PLANTAS VASCULARES & EMBRIÓFITAS \\
\hline FLORES e FRUTOS & TUBO POLÍNICO \\
\hline EMBRIÃO PROTEGIDO & SEMENTES \\
\hline ESPERMATÓFITAS/Plantas que possuem sementes & ALGAS \\
\hline FILOIDE, CAULOIDE e RIZOIDE & ANGIOSPERMAS \\
\hline VASOS CONDUTORES DE SEIVA (XILEMA e FLOEMA) & GIMNOSPERMAS \\
\hline INDEPENDÊNCIA DA ÁGUA PARA A REPRODUÇÃO & PTERIDÓFITAS \\
\hline FOLHA, CAULE e RAÍZ VERDADEIROS & BRIÓFITAS \\
\hline CLOROPLASTO & AUTÓTROFOS \\
\hline
\end{tabular}

Health and Biosciences, v.1, n.3, Dez. 2020

Disponível em: https://periodicos.ufes.br/healthandbiosciences

pág. 118 
Professor/Sugestão: As dezoito palavras e frases indicadas no quadro 2 devem ser destacadas e colocadas num envelope junto com o modelo de cladograma (Figura 3).

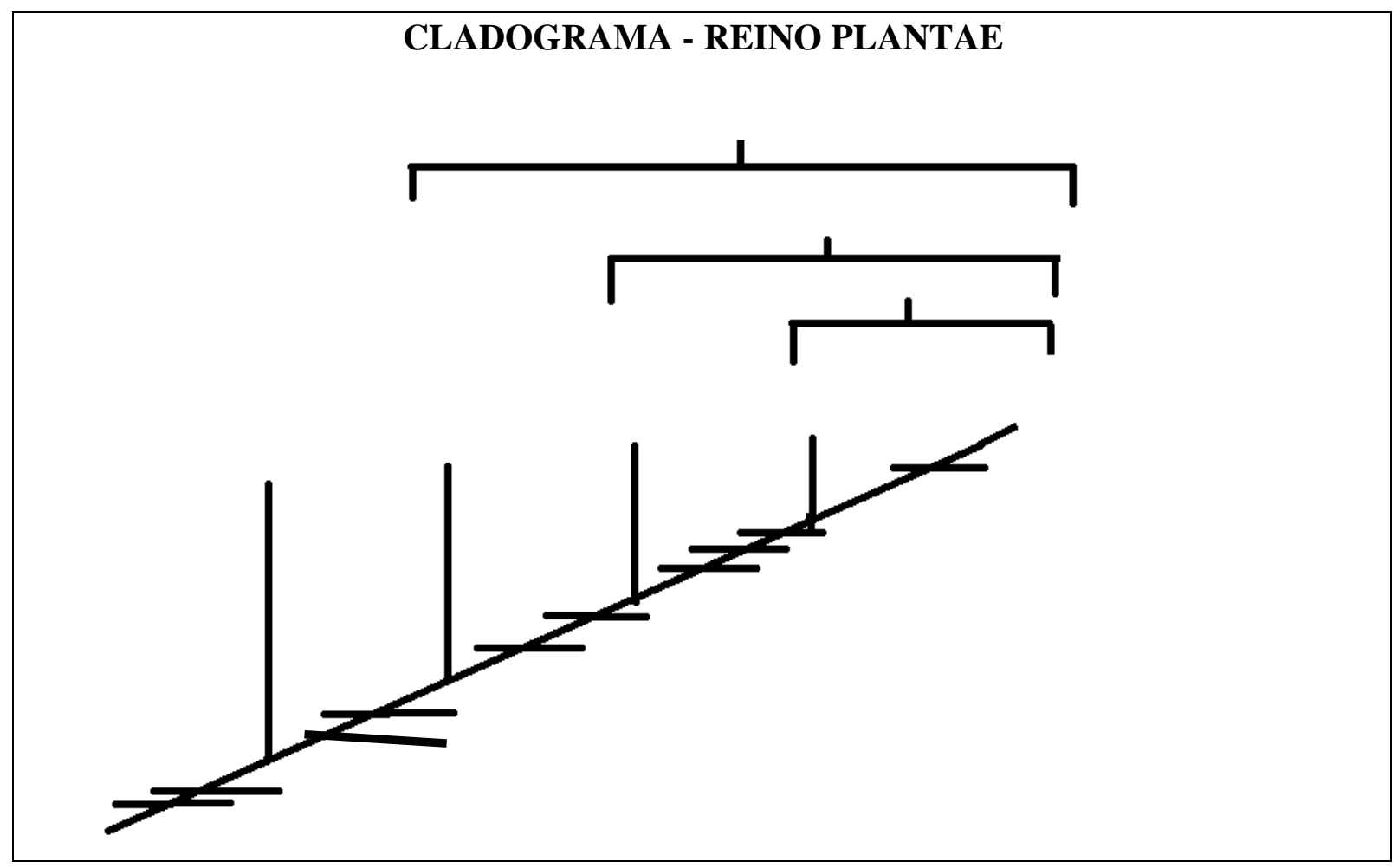

Figura 3. Envelope da evolução - Cladograma das Plantas.

- Após a montagem do cladograma, deve ser feita a discussão dos resultados com os alunos, questionando-os em relação a ordem das características inseridas no cladograma.

Sugestão para o professor: Neste momento poderão ser introduzidos termos mais recentes e incomuns aos alunos como o grupo das Monilófitas e das Licófitas, utilizando um modelo mais atual de classificação das plantas (cladograma), desmistificando conhecimentos inadequados e aprofundando o conteúdo.

$O B S$ : Ao final, pode-se fazer uma exposição dos trabalhos realizados no pátio da escola.

\section{PONTOS INVESTIGATIVOS DA ATIVIDADE}

A atividade investigativa "Identificando os grupos de plantas do entorno escolar e residencial" permite ao aluno a quebra de paradigmas na botânica, onde a partir da observação,

Health and Biosciences, v.1, n.3, Dez. 2020

Disponível em: https://periodicos.ufes.br/healthandbiosciences 
curiosidade, análise, discussão em grupo, pesquisa e dos questionamentos, eles possam refletir sobre a existência, importância e reconhecimento das plantas como seres vivos. Quando os alunos são convidados a fotografar e a pesquisar dados para elaboração da ficha técnica a aprendizagem é autônoma, pois a partir da observação haverá a construção de um novo conhecimento e ao serem questionados sobre a existência e a presença dos grupos de plantas que foram identificados, em maior e menor quantidade, os alunos terão que propor uma explicação, a partir de um problema, e construir um novo conhecimento baseado nas suas observações e discussão com os colegas. Quando os alunos são desafiados a construir/montar o cladograma da evolução das plantas eles são protagonistas do seu próprio aprendizado, uma vez que são estimulados a pensar, raciocinar criticamente, relacionar e analisar características presentes e ausentes na evolução das plantas, construindo, assim, elementos fundamentais para o processo investigativo.

\section{CONSIDERAÇÕES}

A atividade prática investigativa "Identificando os grupos de plantas terrestres presentes no ambiente escolar e residencial" surgiu com o intuito de tornar o ensino de Botânica mais prazeroso e atrativo, a partir da observação, da prática e do estímulo à curiosidade. Nesse sentido, pensou-se em "Como elaborar uma atividade prática investigativa que fosse viável (abordando o máximo de conteúdos), interessante, de baixo custo e que utilizasse poucas aulas".

Inicialmente, a intenção era fotografar apenas imagens do ambiente escolar, mas os alunos sugeriram fotografar também as plantas presentes no entorno residencial, podendo assim trabalhar a relação da diversidade de espécies. Assim, a proposta da criação/elaboração do cladograma surgiu durante o desenvolvimento da atividade prática investigativa, quando os alunos questionaram o professor sobre a presença e ausência de frutos na planta e "o porquê de algumas plantas terem e outras não". Nesse sentido, percebeu-se a necessidade de abordar, incluir e enfatizar a evolução das plantas assim como o processo de polinização, enriquecendo o conteúdo a ser abordado.

$O B S$ : Com os questionamentos feitos pelos alunos foi possível enfatizar itens referentes à evolução, como reprodução e dispersão, sendo algo essencial para o sucesso evolutivo e conquista do ambiente terrestre.

Health and Biosciences, v.1, n.3, Dez. 2020

Disponível em: https://periodicos.ufes.br/healthandbiosciences 


\section{AGRADECIMENTOS}

O presente trabalho foi realizado com o apoio da Coordenação de Aperfeiçoamento de Pessoal de Nível Superior - Brasil (CAPES) - Código de financiamento 001.

\section{REFERÊNCIAS BIBLIOGRÁFICAS}

1. ARRAIS MGM, SOUSA GM, MARSUA MLA. O ensino de botânica: Investigando dificuldades na prática docente. Rev SBEnBio 7: 5409-5418, 2014.

2. BUCKERIDGE M. Árvores urbanas em São Paulo: planejamento, economia e água. Est Avançados 29: 85-101, 2015.

3. MELO EA, ABREU FF, ARAÚJO MIO. A aprendizagem de botânica no ensino fundamental: dificuldades e desafios. Sci Plena 8(10): 1-8, 2012.

4. NEVES A, BÜNDCHEN M, LISBOA CP. Cegueira botânica: é possível superá-la a partir da Educação? Ciênc educ (Bauru) 25(3): 745-762, 2019.

5. SALATINO A, BUCKERIDGE M. “Mas de que te serve saber botânica?”. Est Avançados 30(87): 177-96, 2016.

6. URSI S, BARBOSA PP, SANO PT, BERCHEZ FAS. Ensino de Botânica: conhecimento e encantamento na educação científica. Est Avançados 32(94): 7-24, 2018. 